\title{
The mariner transposable element in the Drosophilidae family
}

\author{
FREDERIC BRUNET, FABIENNE GODIN, JEAN R. DAVID \& PIERRE CAPY* \\ Laboratoire Populations, Génétique et Evolution, CNRS, 91198 Gif/Yvette Cedex, France
}

\begin{abstract}
The distribution of the mariner transposable element among Drosophilidae species was investigated using three different techniques, i.e. squash blots, Southern blots and PCR amplification, using two sets of primers (one corresponding to the Inverted Terminal Repeats and the other to two conserved regions of the putative transposase). Our results and those of others show that the distribution of mariner is not uniform and does not follow the phylogeny of the host species. An analysis of geographical distribution, based on endemic species, shows that mariner is mainly present in Asia and Africa. At least two hypotheses may be proposed to explain the specific and geographical distributions of this element. Firstly, they may be the results of several horizontal transmissions between Drosophila species and/or between Drosophila species and one or several donor species outside the Drosophilidae family. Secondly, these particular distributions may correspond to the evolution of the mariner element from an ancestral copy which was present in the ancestor of the Drosophilidae family.
\end{abstract}

Keywords: Drosophila, mariner, transposon, phylogeny.

\section{Introduction}

The distribution of the mariner transposable elements in Drosophila was previously investigated by Maruyama \& Hartl (1991a). In their analysis, species belonging to different groups, subgenera and genera were screened, showing a distribution with a major gap between the melanogaster group and the Zaprionus subgenus. On the basis of this specific distribution and of the high similarities of DNA sequences of copies extracted from different species, it was suggested that horizontal transfers had occurred between $D$. mauritiana and $Z$. tuberculatus or between species related to these.

The horizontal transfer hypothesis is commonly suggested from the analysis of transposable element distributions and from the comparison of their sequences (Daniels et al., 1990; Mizrokhi \& Mazo, 1990; Lawrence et al., 1992; Robertson, 1993). On the other hand, several alternative hypotheses, among which genetic drift, existence of ancestral elements on which high selective constraint may act in a small part of the element, ancestral polymorphism, different rates of evolution according to the activity level of the copies and according to the host species, could also explain the phylogenetic oddities of several elements (Capy et

*Correspondence. al., 1994). In all cases, the evolutionary history of these elements is not simple and more information is necessary about the variability within and between more or less closely related species.

In this respect, we have investigated the Drosophilidae family to extend the previous work of Maruyama \& Hartl (1991a), which included 78 species. The number of species analysed in this family is now 127 . For several groups, we have screened almost all the available species. Moreover, three more or less sensitive techniques, i.e. squash blots, Southern blots and PCR (polymerase chain reaction) have been used here while Maruyama \& Hartl (1991a) only used a Southern blot detection.

The aim of this analysis was to obtain a better idea of the specific and geographical (based on endemic species) distributions of the mariner element. This is a first step before a detailed analysis, at the nucleotidic level, of the polymorphism within and between species. Our results show that some mariner-related sequences can be detected in many Drosophila species. Moreover, in many species, a particular class of deleted elements seems to represent the major part of the copies. However, in different species, different classes of deleted elements exist. The geographical and specific distributions among species will be discussed with reference to the different hypotheses reviewed by Capy et al. (1994). 


\section{Materials and methods}

\section{Species}

Eighty-three species belonging to the Drosophilidae family were screened. Most of them belong to the huge Drosophila genus. This genus is subdivided into subgenera among which two, the Sophophora and Drosophila subgenera, contain a large number of species. These subgenera are themselves classically divided into groups (e.g. the melanogaster or the obscura groups) and groups containing too many species are subdivided into subgroups (e.g. the melanogaster or the ananassae subgroups).

Particular attention was paid to the ananassae and montium subgroups belonging to the melanogaster group, to the obscura group and to the Zaprionus genus. Moreover, three other genera, Chymomyza, Scaptodrosophila and Scaptomyza, were also considered. Among the 83 species here analysed, 34 were in common with Maruyama \& Hartl (1991a).

\section{Squash blots and Southern blots}

Squash blots were performed as described by Tchen $e t$ al. (1985). For Southern blots, DNA was extracted from about 20-30 flies using the technique of Maruyama \& Hartl (1991a). Total DNA was then digested by HindIII and BamHI, two restriction enzymes that do not cut in the peach sequence, an inactive element described in $D$. mauritiana (Jacobson et al., 1986). Gels were transferred according to the Southern technique (Southern, 1975) and probed with a mixture of pchIV and pchV probes described in Maruyama \& Hartl (1991a).

\section{PCR amplifications}

PCR amplifications were performed using two sets of primers (Fig. 1). Firstly, the inverted repeats of the $D$. mauritiana peach element and, secondly, primers corresponding to the WVPHEL and YSPDLAP conserved regions in the putative transposase (see Robertson, 1993; Langin et al., 1994). These particular primers deduced from the comparison of mos-1 (an active mariner element of $D$. mauritiana, Bryan et al., 1987) and $M L E$ (an inactive mariner-like element of the lepidopteran Hyalophora cecropia, Lidholm et al., 1991), will be called the 'internal primers'. The PCR amplification was performed as follows: less than $10 \mathrm{ng}$ of DNA from regular DNA extraction or $1 \mu \mathrm{L}$ of a rough extraction following the protocol of Gloor \& Engels (1991) were used in $50 \mu \mathrm{L}$ of a total reaction volume containing 0.5 units of Taq polymerase (Promega). Amplifications were performed on the Trio-Thermoblock of Biometra. Prior to the first cycle, a denaturation at $95^{\circ} \mathrm{C}$ during 5 min was performed, then the basic cycle corresponded to a denaturation at $95^{\circ} \mathrm{C}$ for $30 \mathrm{~s}$, an annealing phase at $52^{\circ} \mathrm{C}$ for $1 \mathrm{~min}$ and an elongation phase at $72^{\circ} \mathrm{C}$ for $2 \mathrm{~min}$. After the last cycle, the temperature was decreased to $4^{\circ} \mathrm{C}$. The total number of cycles varied between 35 and 40 . To be sure that the amplified fragments were related to mariner, the gels with the PCR products were transferred on a nylon filter and hybridized with mariner probes of D. mauritiana as for squash blots and Southern blots.

\section{Results}

Investigations were mostly carried out on species of the Sophophora subgenus of Drosophila, i.e. the ananassae and the montium subgroups within the melanogaster group, the obscura group and on species of Zaprionus with its two subgenera (Zaprionus and Anaprionus). Several other species randomly sampled from the Drosphilidae family were also tested.

\section{The ananassae subgroup}

Twelve of the 20 species known in this subgroup have been screened. Detailed results are summarized in

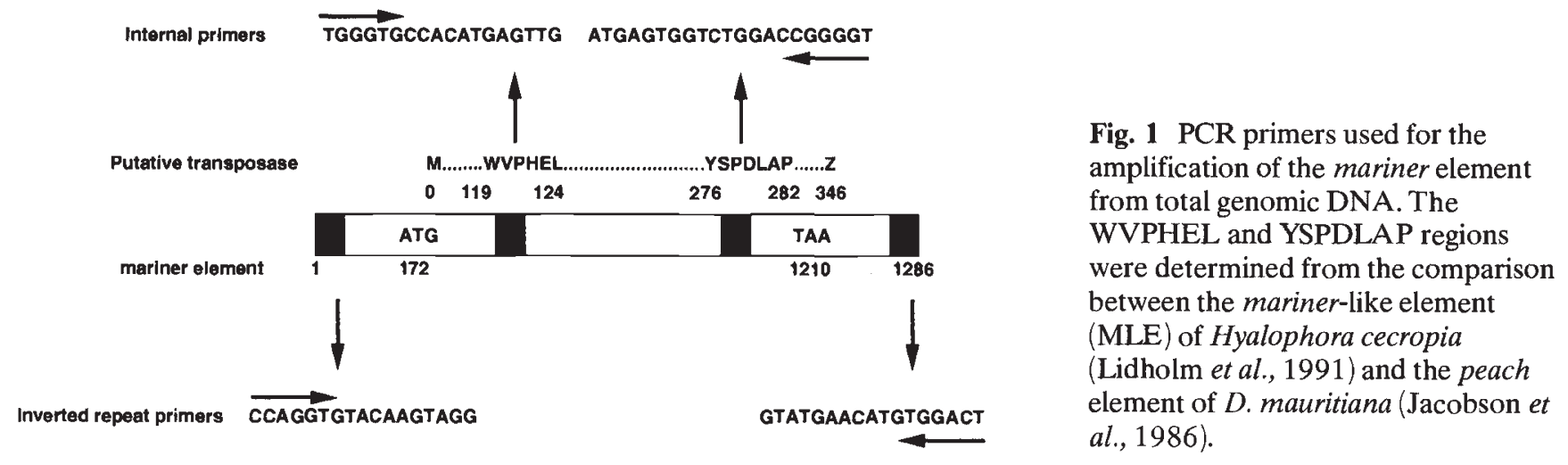


Table 1 Distribution of the mariner element detected by three different techniques in the species of the ananassae subgroup in the melanogaster group

\begin{tabular}{|c|c|c|c|c|}
\hline \multirow[b]{2}{*}{ Species } & \multirow{2}{*}{ Squash blot } & \multirow{2}{*}{$\begin{array}{l}\text { Southern blot } \\
\text { (no. of bands) }\end{array}$} & \multicolumn{2}{|c|}{ PCR } \\
\hline & & & ITR & NT \\
\hline \multicolumn{5}{|l|}{ bipectinata complex } \\
\hline D. bipectinata & ++ & $1-2$ & + & + \\
\hline D. malerkotliana & +++ & 9 & + & + \\
\hline D. parabipectinata & ++ & $10-15$ & + & + \\
\hline D. pseudoananassae & ++ & 0 & + & + \\
\hline \multicolumn{5}{|l|}{ ananassae complex } \\
\hline D. ananassae & ++ & $3-5$ & + & + \\
\hline D. atripex & +++ & 8 & + & + \\
\hline D. monieri & $+1-$ & 7 & + & + \\
\hline D. ochrogaster & & & + & + \\
\hline \multicolumn{5}{|l|}{ ercepeae complex } \\
\hline D. ercepeae & ++++ & $10-20$ & + & + \\
\hline D. vallismaia & & $15-20$ & + & + \\
\hline D. n.sp. Madagascar & + & 5 & & \\
\hline \multicolumn{5}{|l|}{ Ungrouped species } \\
\hline D. varians & + & 2 & + & - \\
\hline
\end{tabular}

A blank means that the technique was not used.
Table 1. The species are distributed among the four complexes of this subgroup, i.e. the bipectinata (four species), the ananassae (four species), the ercepeae (three species) and the nonclassified species (one species) complexes. In this subgroup, only two species were previously screened by Maruyama \& Hartl (1991a).

The three techniques of detection were used for all species. For most of them, some positive signals were observed (Fig. 2). The only exception is $D$. varians (nonclassified species) for which no amplification was obtained with internal primers. The hybridization signals and the numbers of bands observed by Southern blots vary greatly from one species to another. Assuming that, in this subgroup, the two restriction endonucleases used do not cut into the mariner copies, our results suggest that the number of copies is highly variable. Indeed, estimations of the number of copies, based on the number of bands observed by Southern blots, show that this number could vary from 1 to 2 in $D$. bipectinata and $D$. varians to 10 to 20 in the species of the ercepeae complex. For $D$. monieri no signal was detected by squash blot while faint hybridizing bands were observed by Southern blot. The main difference between these two tech-
Fig. 2 Southern blot hybridizations. In each case, the total genomic DNA was extracted from about 20-30 individuals using the technique described by Maruyama \& Hartl(1991a). In the Anaprionus subgenus very faint bands are detected.
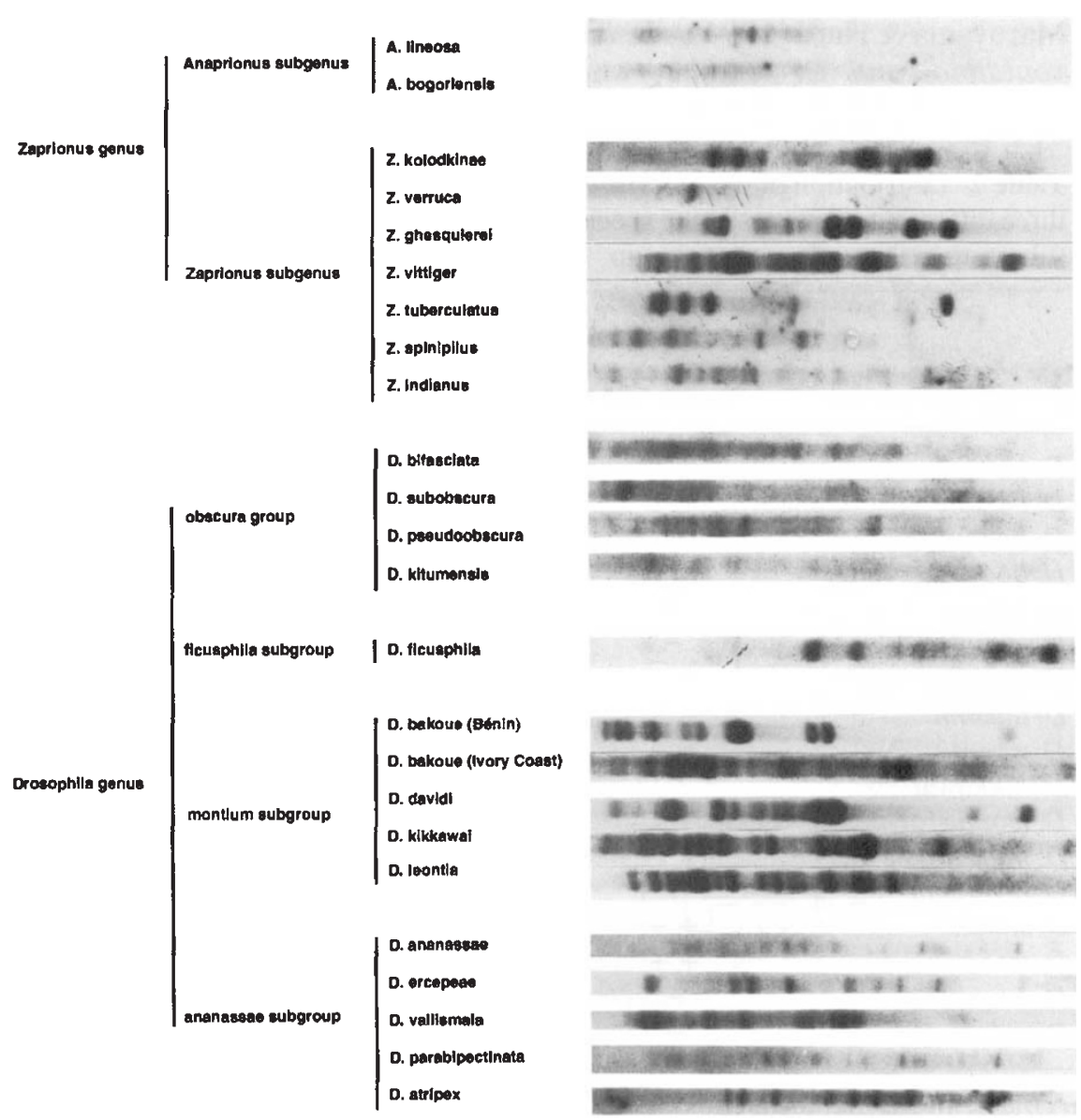
niques was that the washing stringency was generally higher for the former compared with the latter. Therefore, it is possible that the similarity between the mariner copies of this species and the D. mauritiana probe is lower than for the copies detected in the other species of this subgroup.

\section{The montium subgroup}

In this subgroup, 14 species were previously screened by Maruyama \& Hartl (1991a). In the present work, 18 species were tested corresponding to 13 newly investigated species and five species already analysed. The results are given in Table 2 and some hybridizations are shown in Fig. 2.

Considering the species in common, the results of the two analyses are in agreement with the exception of D. serrata. Here, Maruyama \& Hartl (1991a) found a positive signal by Southern blot whereas we failed to find anything with the three techniques used. However, because two different strains were used, it is possible that this species is polymorphic for the presence or absence of the element.

With regard to the new species, the montium subgroup is quite heterogeneous. Several species seem to be free of the mariner element $(D$. auraria from Maruyama \& Hartl (1991a), D. burlai, D. chauvacae, D vouidibioi and $D$. vulcana) whereas several others

Table 2 Distribution of the mariner element detected by three different techniques in the species of the montium subgroup in the melanogaster group

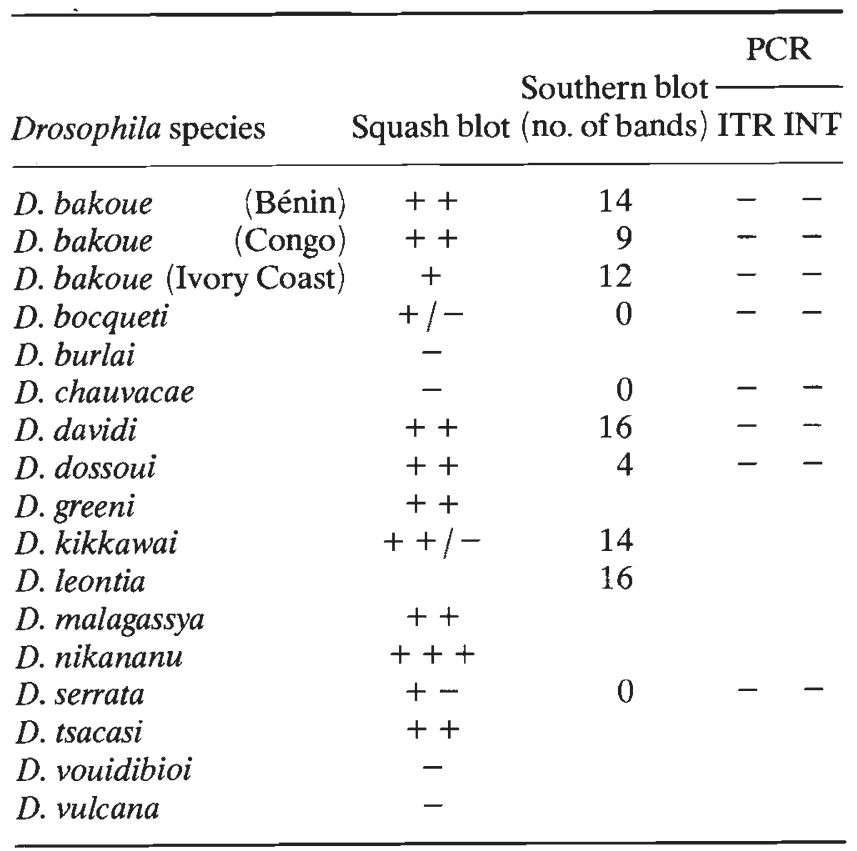

A blank means that the technique was not used. contain a large number of copies (assuming that no restriction sites for HindIII and BamHI exist in these copies). Such is the case for D. bakoue, D. davidi, $D$. kikkawai and $D$. leontia in which the average number of copies is about 14 . All these copies were detected by Southern blots. By PCR amplification, no product was obtained for the eight species tested, using either set of primers. Therefore, the elements detected may correspond to deleted copies (in particular in the regions of the PCR primers). On the other hand, while these copies are easily detectable by Southern hybridization, it is possible that the divergence with the $D$. mauritiana elements is strong enough to prevent the hybridization of the PCR primers.

\section{Other subgroups in the melanogaster group}

Within the melanogaster group, some mariner-like elements were detected in seven out of the eight subgroups analysed (Fig. 3). Only the elegans and eugracilis subgroups appear to be free of such elements. In the takahashii subgroup, some elements seem to be present in $D$. lutescens and $D$. pseudotakahashii but not in $D$. takahashii itself. Therefore, the mariner elements seem to be randomly distributed within and between the different subgroups which compose this group. Moreover, the hybridization intensities vary from one species to another. Such a result could be explained by different degrees of similarities with the $D$. mauritiana probe. In this case, it will be interesting to sequence several of these elements to determine their phylogenetic relationships.

\section{The obscura group}

This group, which also belongs to the same Sophophora subgenus, was previously investigated by Maruyama \& Hartl (1991a). However, none of the six species analysed contained any mariner copies. In the present work, 10 species were tested, three of them being in common with the previous investigation. In contrast with the previous results, all the species tested seem to harbour some mariner elements (Table 3 ). The main difference between the two investigations is probably the washing stringency of the hybridized filters. Therefore, it is quite possible that the elements detected in this group are more divergent from those of $D$. mauritiana. It must be stressed, however, that some amplifications were obtained using the PCR primers corresponding to the ITR.

\section{The Drosophila, Zaprionus and other genera}

For the remaining species tested belonging to the Drosophila genus, the results are summarized in Table 


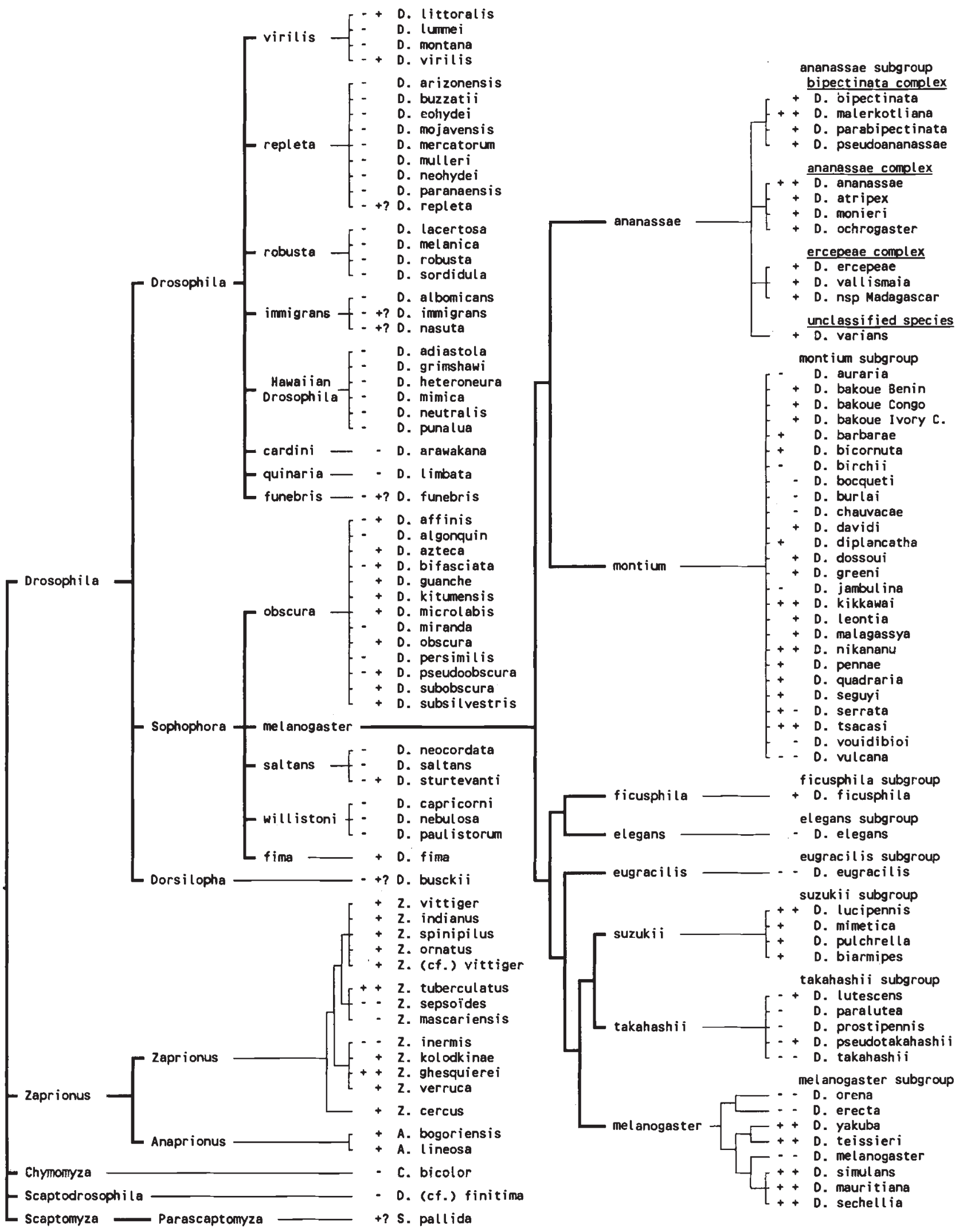

Fig. 3 Summary of the different results obtained by Maruyama \& Hartl (1991a), in the left column, and in the present work, right column. + , existence of hybridizing signal(s); - , no hybridizing signal. 
Table 3 Distribution of the mariner element detected by three different techniques in the species of the obscura group

\begin{tabular}{|c|c|c|c|c|}
\hline \multirow[b]{2}{*}{ Drosophila species } & \multirow[b]{2}{*}{ Squash blot } & \multirow{2}{*}{$\begin{array}{l}\text { Southern blot } \\
\text { (no. of bands) }\end{array}$} & \multicolumn{2}{|c|}{ PCR } \\
\hline & & & ITR & INT \\
\hline \multicolumn{5}{|l|}{ Palaeartic species } \\
\hline D. bifasciata & + & 12 & ++ & \\
\hline D. guanche & + & & & \\
\hline D. obscura & + & & + & \\
\hline D. subobscura & + & 5 & + & \\
\hline D. subsilvestris & + & & & \\
\hline \multicolumn{5}{|l|}{ American species } \\
\hline D. affinis & + & & ++ & \\
\hline D. azteca & + & & & \\
\hline D. pseudoobscura & + & 8 & & \\
\hline \multicolumn{5}{|l|}{ African species } \\
\hline D. kitumensis & + & 5 & - & + \\
\hline D. microlabis & + & & & \\
\hline
\end{tabular}

A blank means that the technique was not used.

Table 4 Distribution of the mariner element detected by three different techniques in some species of the Drosophila genus

\begin{tabular}{|c|c|c|c|c|}
\hline \multirow[b]{2}{*}{ Drosophila genus } & \multirow{2}{*}{$\begin{array}{c}\text { M \& H } \\
\text { Southern } \\
\text { blot }\end{array}$} & \multirow{2}{*}{$\begin{array}{l}\text { Squash } \\
\text { blot }\end{array}$} & \multicolumn{2}{|c|}{ PCR } \\
\hline & & & ITR & INT \\
\hline \multicolumn{5}{|l|}{$\begin{array}{l}\text { Sophophora subgenus } \\
\text { saltans group }\end{array}$} \\
\hline $\begin{array}{l}\text { D. sturtevanti } \\
\text { fima group }\end{array}$ & - & $+1-$ & & \\
\hline $\begin{array}{l}\text { D. fima } \\
\text { Drosophila subgenus }\end{array}$ & & +++ & & \\
\hline $\begin{array}{l}\text { virilis group } \\
\text { D. littoralis }\end{array}$ & - & +++ & & \\
\hline $\begin{array}{l}\text { D. virilis } \\
\text { repletagroup }\end{array}$ & - & ++ & & $+?$ \\
\hline $\begin{array}{l}\text { D. repleta } \\
\text { immigrans group }\end{array}$ & - & & & $+?$ \\
\hline D. immigrans & - & $+1-$ & & $+?$ \\
\hline $\begin{array}{l}\text { D. nasuta } \\
\text { funebris group }\end{array}$ & - & & & $+?$ \\
\hline $\begin{array}{l}\text { D. funebris } \\
\text { cardini group }\end{array}$ & - & & $+?$ & \\
\hline $\begin{array}{l}\text { D. arawakana } \\
\text { quinaria group }\end{array}$ & & - & & \\
\hline D. limbata & & - & & \\
\hline $\begin{array}{l}\text { Dorsilopha subgenus } \\
\text { D. busckii }\end{array}$ & - & - & & + ? \\
\hline
\end{tabular}

M \& H Southern blot refers to the work of Maruyama \& Hartl (1991a).

A blank means that the technique was not used.
4. Among these data we can observe the putative absence of mariner in $D$. arawakana (cardini group) and in $D$. limbata (quinaria group) whereas some hybridization was obtained on $D$. fima genomic DNA (fima group). Moreover, a few species seem to be positive while they appeared negative from the Maruyama \& Hartl (1991a) analysis, e.g. D. virilis and D. littoralis (virilis group).

Concerning the Zaprionus genus, two species belonging to the Anaprionus subgenus and 13 species of the Zaprionus subgenus were tested (Table 5). With the exception of $Z$. sepsoïdes, $Z$. mascariensis and $Z$. inermis, all the species showed some hybridising bands with $D$. mauritiana probes. The signals are generally weak in the Anaprionus subgenus but can be strong in the Zaprionus subgenus for almost all the positive species. This result suggests a better identity between $D$. mauritiana and the species of the Zaprionus subgenus than with the two species of the Anaprionus subgenus.

Concerning the species belonging to the three other genera (Chymomyza, Scaptodrosophila and Scaptomyza) no signal was detectable by Southern hybridization. However, some amplification products were obtained from total genomic DNA of Scaptomyza pallida using the two sets of primers.

\section{Discussion \\ Detection of the elements}

Figure 3 summarizes all the data concerning the distribution of the mariner element among the species of the Drosophilidae family. The data of Maruyama \& Hartl (1991a) and of the present work were pooled. It appears that some gaps exist and that the element can be present in a given species but absent in a closely related one. Such is the case between the species of the montium subgroup. Moreover, in the melanogaster subgroup, our results confirm those of Maruyama \& Hartl (1991a), i.e. the absence of the mariner element in D. melanogaster, D. erecta and D. orena.

In this respect, it must be stressed that it is not possible to state that a species is free of the mariner element. For instance, in the present study the genomic DNAs of the species tested were probed using the $D$. mauritiana sequences as a reference. In other words, if a species contains some homologous sequences which are homologous but diverged strongly from our reference sequence, it will be difficult to detect them. That is the reason why, complementing the classical analysis by squash and Southern blots, some investigations by PCR amplification were performed using two sets of primers taken from regions suspected to evolve at a slower rate than the other parts of the element. 
Table 5 Distribution of the mariner element detected by three different techniques in the species of the Zaprionus genus and other related genera

\begin{tabular}{|c|c|c|c|c|c|}
\hline \multirow[b]{3}{*}{ Species } & \multirow{3}{*}{$\begin{array}{c}M \& H \\
\text { Southern blot }\end{array}$} & \multicolumn{2}{|c|}{ Present study } & \multirow{2}{*}{\multicolumn{2}{|c|}{ PCR }} \\
\hline & & Squash blot & Southern blot & & \\
\hline & & & (no. of bands) & ITR & INT \\
\hline \multicolumn{6}{|l|}{ Zaprionus genus } \\
\hline \multicolumn{6}{|l|}{ Zaprionus subgenus } \\
\hline$Z$. indianus $(=Z$. collarti $)$ & & +++ & $10-20$ & $+(700 \mathrm{bp})$ & - \\
\hline Z. ornatus & & ++ & & & \\
\hline Z. spinipilus & & ++ & $7-12$ & + & + \\
\hline Z. vittiger & & ++ & $15-20$ & + & \\
\hline Z. (cf.) vittiger (Cape Town) & & ++ & & & \\
\hline Z. mascariensis & &. & 0 & & \\
\hline Z. sepsoïdes & - & - & 0 & & \\
\hline Z. tuberculatus & + & ++ & $2-7$ & + & + \\
\hline Z. ghesquieri & + & ++ & $6-13$ & + & + \\
\hline Z. inermis & - & - & 0 & + & + \\
\hline Z. kolodkinae & & & $3-6$ & & \\
\hline Z. verruca & & ++ & $2-3$ & $+(1800 \mathrm{bp})$ & + \\
\hline Z. cercus & & & 0 & + & + \\
\hline \multicolumn{6}{|l|}{ Anaprionus subgenus } \\
\hline A. bogoriensis & & ++ & 5 & & \\
\hline A. lineosa & & & 11 & & \\
\hline \multicolumn{6}{|l|}{ Chymomyza genus } \\
\hline C. bicolor & & - & & - & - \\
\hline \multicolumn{6}{|l|}{ Scaptodrosophila genus } \\
\hline D. (cf.) finitima & & - & & & \\
\hline \multicolumn{6}{|l|}{ Scaptomyza genus } \\
\hline \multicolumn{6}{|l|}{ Parascaptomyza subgenus } \\
\hline S. pallida & & & & + & + \\
\hline
\end{tabular}

M \& H Southern blot refers to the work of Maruyama \& Harth (1991a).

A blank means that the technique was not used.

Fig. 4 Geographical distribution of the mariner-like elements based on the distribution of endemic species of the Drosophilidae family.

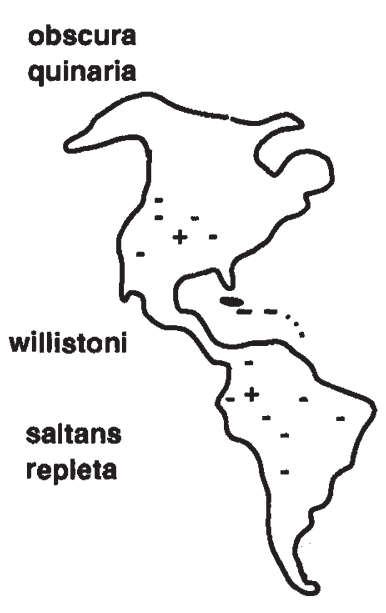

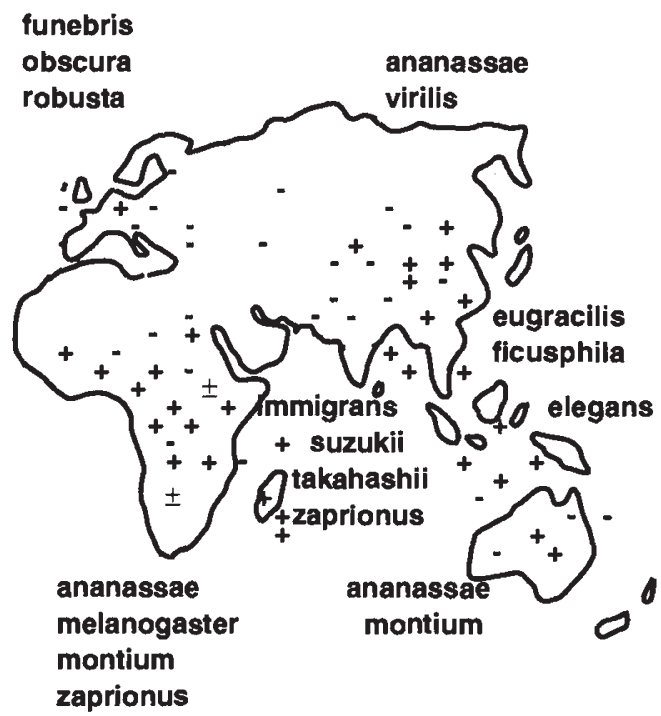




\section{Geographical distribution}

To try to understand the origin of the mariner element in the Drosophilidae family, its geographical distribution was analysed considering only endemic species. This compilation, summarized in Fig. 4, shows that mariner is mainly present on the Asiatic and the African continents. In other words, with the exception of species belonging to the obscura group, none of the species endemic to the Palaearctic region and to the American continent contains any mariner element hybridizing with the $D$. mauritiana probes.

\section{Evolutionary hypotheses}

At least two hypotheses may be proposed to interpret the results. Firstly, the apparent random distribution between species of this element and its restricted geographical distribution suggest the existence of horizontal transmission. Such a phenomenon has already been proposed by Maruyama \& Hartl (1991b) to explain the high similarity observed between the sequences of Zaprionus and some species of the melanogaster subgroup. However, to explain the complete mariner distribution among the Drosophilidae, it must be assumed that this phenomenon was relatively frequent. On the other hand, the geographical distribution restricted to the Asiatic and to the African continents also suggests a repeated introduction of this element by horizontal transmission in species endemic in these regions.

The second hypothesis which can be proposed is that the mariner element is an ancient element, as suggest by Kidwell (1993) and by Robertson (1993). In this respect, assuming that a mariner element was present in the ancestor of the family Drosophilidae, the random distribution of this element among the species of this family can be interpreted as the result of loss in some lineages. For instance, Kaplan et al. (1985) showed that it is possible to lose a transposable element by genetic drift when the average number of copies is relatively low. We also may consider that if, in a species, all the elements become inactive they will be easily lost by genetic drift.

Throckmorton (1975) and Wheeler (1981) suggested that the origin of the Drosophilidae family was probably in south-east Asia. Therefore, the hypothesis of an ancestral origin of the mariner element in this family is reinforced by its geographical distribution. Indeed, it is quite possible that mariner was lost in several lineages during speciation, as stated above, but also during the colonization of the new area. Thus, this could explain the absence of mariner in the Palaearctic region and on the American continent.

These two hypotheses are not mutually exclusive and it is quite possible that a mariner element was present in the ancestor of the Drosophilidae family, that it was lost in some lineages and was reacquired by horizontal transmission. In this respect, analysing mariner in other insects, Robertson (1993) showed the presence of different types of mariner in several species suggesting the existence of several mariner subfamilies. Therefore, even if mariner were an ancient element, it could be reacquired several times from several donors by horizontal transmission. Thus, we need more information, especially on sequence polymorphism within and between more or less related species.

\section{Note added in proof}

The presence of the mariner element in $D$. erecta (melanogaster subgroup) has been recently mentioned by A. R. Lohe, E. N. Moriyamo, D. A. Lidholm and D. L. Hartl (manuscript submitted). The copies sequenced are 97 per cent identical to those of the cat flea Ctenocephalides felis, and 50 per cent divergent from the Mos-1 element of $D$. mauritiana. This result strongly suggests the existence of horizontal transmission. This could explain why these copies were not detected with the mauritiana probes used in this work.

\section{Acknowledgements}

We thank the anonymous referees from their helpful comments. This work has benefitted from CNRS/NSF (no. 693) and GREG (no. 48) grants.

\section{References}

BRYAN, G. J., JACOBSON, J. W. AND HARTL, D. L. 1987. Heritable somatic excision of a Drosophila transposon. Science, 235, 1636-1638.

CAPY, P., ANXOLABÉHERE, D. AND LANGIN, T. 1994. The strange phylogenies of transposable elements: are horizontal transfers the only explanation? Trends Genet., 10, 7-12.

DANIELS, S. B., PETERSON, K. R., STRAUSBAUGH, L. D., KIDWELL, M. G. AND CHOVNICK, A. 1990. Evidence for horizontal transmission of the $P$ element between Drosophila species. Genetics, 124, 339-355.

GLOOR, G. AND ENGELS, w. 1991. Single-fly DNA preparations for PCR. Drosph. Inf. Serv., 17-18.

JACOBSON, J. w., MEDHORA, M. M. AND HARTL, D. L. 1986. Molecular structure of a somatically unstable element in Drosophila. Proc. Natl. Acad. Sci. U.S.A., 83, 8684-8688.

KAPLAN, N., DARDEN T. AND LANGLEY, C. H. 1985. Evolution and extinction of transposable elements in Mendelian populations. Genetics, 109, 459-480.

KIDWELL. M. G. 1993. Voyage of an ancient mariner. Nature, 362, 202-202.

LANGIN, T., CAPY, P. AND DABOUSSI, M. J. 1994. The transposable element, Impala, a fungal member of the Tc1-mariner super family. Mol. Gen. Genet. (in press). 
LAWRENCE, J. G., OCHMAN, H. AND HARTL, D. L. 1992. The evolution of insertion sequences within enteric bacteria. Genetics, 131, 9-20.

LIDHOLM, D. A., GUDMUNDSSON, G. H. AND BOMAN, H. G. 1991. A highly repetitive mariner-like element in the genome of Hyalophora cecropia. J. Biol. Chem., 266, 11518-11521.

MARUYAMA, K. AND HARTL, D. L. 1991a. Evolution of the transposable element mariner in Drosophila species. Genetics, 128, 319-329.

MARUYAMA, K. AND HARTL, D. L. 1991b. Evidence for interspecific transfer of the transposable element mariner between Drosophila and Zaprionus. J. Mol. Evol., 33, 514-524.

MIZROKHI, L. J. AND MAZO, A. M. 1990. Evidence for horizontal transmission of the mobile element jockey between distant Drosophila species. Proc. Natl. Acad. Sci. U.S.A., 87, 9216-9220.
ROBERTSON, H. M. 1993. The mariner transposable element is widespread in insects. Nature, 362, 241-245.

SOUTHERN, E. M. 1975. Detection of specific sequences among DNA fragments separated by gel electrophoresis. $J$. Mol. Biol., 98, 503-517.

TCHEN, P., ANXOLABÉHËRE, D., NOUAUD, D. AND PERIQUET, G. 1985. Hybridization on squashed flies: a method to detect genes sequences in single Drosophila individuals. Analyt. Biochem., 150, 415-420.

THROCKMORTON, L. H. 1975. The phylogeny, ecology and geography of Drosophila. In: King, R. C. (ed.) Handbook of Genetics, vol. 3, pp. 421-469. Plenum Press, New York. WHEELER, M. R. 1981. The Drosophilidae: a taxonomic overview. In: Ashburner, M., Carson H. L. and Thompson J. N., Jr. The Genetics and Biology of Drosophila, vol. 3a, pp. 1-97. Academic Press, New York. 